\title{
Fisioterapia e os desafios da Covid-19
}

A pandemia de coronavírus (Covid-19) decretada pela Organização Mundial da Saúde (OMS) há cerca de um ano criou interrupções significativas na vida e no trabalho de todas as pessoas. Não conhecíamos a história natural ou mecanismos da doença, nem as formas de vulnerabilidade, que foram sendo parcialmente identificados e certamente contribuíram gerando resultados melhores para o tratamento dos pacientes, além de mais proteção e segurança aos profissionais de saúde, incluindo os fisioterapeutas, que estiveram desde o início vinculados aos cuidados com os acometidos pelo vírus Sars-CoV-2.

Conhecemos inicialmente o acometimento respiratório, com sintomas como tosse e febre, e posteriormente o comprometimento de outros órgãos e sistemas. Agora também conhecemos as sequelas, já nominadas pela OMS como post-Covid-19 condition. No entanto, ainda não há um tratamento específico disponível. A agressão do vírus ao epitélio respiratório, a intensa resposta inflamatória, o acúmulo de fluido nos alvéolos e a presença de trombos na microcirculação pulmonar geram diferentes graus de desconforto respiratório.

Foi necessário reaprender estratégias de oxigenioterapia e aplicação de ventilação não invasiva, conhecidas por serem eficazes para evitar intubação e, portanto, recomendadas como primeira opção, mas agora sob o risco de dispersão de aerossóis no ambiente e grande potencial de contaminação. Nesse sentido, recente recomendação sugere "equilibrar riscos e benefícios".

Com o objetivo de melhorar os níveis de oxigenação, aprendemos a utilizar com frequência a posição prona, não apenas nos pacientes em ventilação mecânica invasiva, mas também naqueles em respiração espontânea ou em ventilação não invasiva, e mesmo nos pacientes mais difíceis ou com os índices de massa corpórea (IMC) mais elevados.

No entanto, o trabalho do fisioterapeuta no Centro de Terapia Intensivo (CTI) não se resume somente aos cuidados respiratórios: é preciso tratar a fraqueza muscular adquirida na Unidade de Terapia Intensiva (UTI), condição que está associada a piores desfechos e que pode levar à falência respiratória e ao desenvolvimento de síndrome do desconforto respiratório aguda (SDRA).

Como em muitas outras doenças críticas, pacientes pós-Covid-19 podem apresentar dispneia $\mathrm{e}$ fadiga em repouso e durante atividades de vida diária (AVD), disfunção muscular periférica e intolerância ao exercício, além de aumento no risco de desordem pós-traumática, ansiedade e depressão. Os dados disponíveis mostram que as sequelas atingem também aqueles que não tiveram a doença em sua forma severa, com restrição de volumes pulmonares, comprometimento da resistência e da difusão, além de diminuição na distância percorrida no teste de caminhada de seis minutos.

Os sintomas pós-Covid-19 mais frequentes são tosse, febre baixa e fadiga, mas podem incluir também dispneia, dor torácica, dor de cabeça, dificuldades neurocognitivas e tromboembolismo. Muitos pacientes podem recuperar-se nas primeiras seis semanas espontaneamente ou com suporte mínimo, preferencialmente remoto, enquanto aqueles com a forma mais grave da doença e necessidade de internação prolongada têm indicação de realizar reabilitação pulmonar de forma gradual e individualizada, uma vez que o protocolo ideal para esses pacientes ainda não é totalmente conhecido.

A sobrecarga dos serviços de saúde com pacientes vítimas de Covid-19 e a necessidade de isolamento social para conter a circulação do vírus impuseram restrições ao atendimento de outros tipos de pacientes ambulatoriais. Embora modalidades remotas tenham sido implantadas a fim de minimizar as perdas dos pacientes ambulatoriais, respeitando as orientações para distanciamento social durante a pandemia, há uma hesitação compreensível sobre a competência dos fisioterapeutas de exercer a tarefa de forma segura para os pacientes.

Desde o início da pandemia houve uma recomendação para que cada membro das equipes dos CTI não realizasse turnos acima de 6 a 8 horas e que recebessem suporte psicológico. No entanto, sabemos que os profissionais " $\mathrm{da}$ 
linha de frente" trabalham em condições bem diferentes. $\mathrm{O}$ atendimento aos pacientes com Covid-19 exigiu rápida incorporação do conhecimento produzido pela ciência, treinamento de pessoal e cooperação entre os diferentes setores. Na atuação multiprofissional intensa, o papel da fisioterapia tem se destacado na assistência respiratória qualificada. Assim, os fisioterapeutas merecem todo o reconhecimento pela competência e dedicação que os tornaram indispensáveis às equipes de CTI. Nessa luta, é preciso ainda conquistar melhor remuneração para os plantões, para que seja no mínimo comparável a de outros profissionais da saúde.

Ada Clarice Gastaldi Universidade de São Paulo (USP) Faculdade de Medicina de Ribeirão Preto FMUSPRP, Brasil. bttps://orcid.org/0000-0001-9845-3611 